\title{
Intra-individual diversity and similarity of salivary and faecal microbiota
}

Correspondence

Johanna Maukonen

johanna.maukonen@vtt.fi

Received 18 April 2007

Accepted 24 August 2008

\author{
Johanna Maukonen, Jaana Mättö,† Maija-Liisa Suihko and Maria Saarela \\ VTT Technical Research Centre, PO Box 1000, FI-02044 VTT, Finland
}

\section{INTRODUCTION}

Both ends of the orogastrointestinal tract of humans have an abundant microbiota dominated by anaerobically growing bacteria (Berg, 1996). The number of bacteria in the oral cavity is about $10^{11}$ (g wet weight dental plaque $)^{-1}$ and $10^{8}-10^{9}(\mathrm{ml} \text { saliva })^{-1}$ (culturable bacteria; Nisengard \& Newman, 1994; Li et al., 2005), whereas in faeces the corresponding figure is $6-9 \times 10^{10}(\mathrm{~g} \text { wet weight })^{-1}$ (detected with molecular techniques; Thiel \& Blaut, 2005). Although the same bacterial genera can be found in oral and colonic samples, to the best of our knowledge only one intra-individual comparative study of bacterial populations (in this case lactobacilli) of these two sampling sites has been performed previously in humans (Dal Bello \& Hertel, 2006).

The faecal microbiota is dominated by the Clostridium coccoides-Eubacterium rectale (Erec) group, Clostridium leptum group and Bacteroidetes group (Franks et al., 1998; Suau et al., 1999; Sghir et al., 2000; Eckburg et al., 2005), which account for over $70 \%$ of faecal bacteria (Sghir et al., 2000). The bacteria belonging to the Erec group (clostridial

†Present address: Finnish Red Cross Blood Service, Kivihaantie 7, 00310 Helsinki, Finland.

Abbreviations: DDGE, denaturing gradient gel electrophoresis; Erec, Clostridium coccoides-Eubacterium rectale; RAPD, randomly amplified polymorphic DNA. cluster XIVa) (Collins et al., 1994) comprise 10-59\% of the total faecal bacteria depending on the detection method used (Franks et al., 1998; Suau et al., 1999; Sghir et al., 2000; Eckburg et al., 2005; Maukonen et al., 2006a). Bifidobacterium and Lactobacillus, although found in most subjects, comprise smaller populations among faecal bacteria in adults (bifidobacteria, 1-5\%; lactobacilli, $<1-$ $2 \%$; Franks et al., 1998; Sghir et al., 2000). The oral cavity contains different micro-environments (cheeks, palate, tongue, tooth surfaces, gingival areas and saliva), each with their own microbiota (Aas et al., 2005). The salivary microbiota reflects a mixture of bacteria washed off from the various surfaces, especially from the tongue (Nisengard \& Newman, 1994). A large diversity of bacteria has been detected in the oral cavity, including low-mol\% G + Ccontent Gram positive organisms (e.g. streptococci and Clostridia group), fusobacteria, actinobacteria, different proteobacteria, Prevotella, Porphyromonas, Bacteroides and spirochaetes. Members of the clostridial cluster XIVa have occasionally been detected in oral samples (Paster et al., 2001). In the oral cavity, both bifidobacteria and lactobacilli can be detected, but their occurrence is reversed compared with faeces: lactobacilli are a common finding in the oral cavity, whereas bifidobacteria are detected less frequently.

The aim of this study was to investigate whether similar features concerning the diversity and temporal stability of the predominant microbiota and selected bacterial groups 
- namely the clostridial cluster XIVa, bifidobacteria and lactobacilli - could be detected intra-individually in two different niches: the oral cavity and the colon. Special focus was also put on the species distribution of the genera Lactobacillus and Bifidobacterium at these two sites.

\section{METHODS}

Sample handling. Faecal and salivary $(5 \mathrm{ml}$ saliva collected with paraffin stimulation) samples were collected from ten adult volunteers (nine females, one male, aged 34-57 years) at three sampling time points (at baseline before probiotic consumption and after 1 and 2 weeks of probiotic consumption). The subjects consumed a commercial probiotic capsule preparation (Trevis, 54 capsules; Ipex Medical) according to the manufacturer's instructions (three capsules each day) for 2 weeks. Trevis capsules contain a mixture of Lactobacillus acidophilus LaCH-5, Bifidobacterium animalis subsp. lactis $\mathrm{Bb}-12$ and yoghurt starter bacteria, totalling $10^{9}-10^{10}$ organisms per capsule. The main recruiting criterion was a normal intestinal balance (absence of repeating and/or persisting gastrointestinal symptoms). The exclusion criteria were regular gastrointestinal tract symptoms, lactose intolerance, coeliac disease and antimicrobial therapy during the 2 months prior to the study. The study was approved by the ethical committee of the VTT Technical Research Centre of Finland. All subjects gave written informed consent for participation in the study.

Part of the faecal sample was transferred to Cary-Blair transport medium (Atlas, 1997) and part of the salivary sample to VMGA III medium (Rams et al., 1990), and these were analysed by culture within 1-2 days. The stability of the studied bacterial groups in the transport medium was confirmed by culturing four samples immediately after sampling and after storage for 2 days in the appropriate transport medium. The rest of the samples were frozen at $-70{ }^{\circ} \mathrm{C}$ for DNA-based analyses.

\section{Culture-based analysis}

The samples were serially diluted in pre-reduced peptone saline containing $0.5 \mathrm{~g} \mathrm{~L}^{-c y s t e i n e} / \mathrm{HCl} \mathrm{l}^{-1}$ ( $\mathrm{pH} \mathrm{6.3;} \mathrm{Merck)} \mathrm{and} \mathrm{plated} \mathrm{on}$ culture medium in an anaerobic workstation (Don Whitley Scientific). The following culture media and incubation conditions were used (incubation at $37^{\circ} \mathrm{C}$ ): supplemented Brucella blood agar (Tammer-Tutkan Maljat) for anaerobes (anaerobic incubation for 7 days), sheep blood agar for aerobes (Tammer-Tutkan Maljat) (aerobic incubation for 4 days) and Beerens agar for bifidobacteria (Beerens, 1991) (anaerobic incubation for 4 days). For the detection of $B$. animalis subsp. lactis $\mathrm{Bb}-12$, the samples were also acid pretreated (Alander et al., 2001). Rogosa agar was used for the detection of lactobacilli (anaerobic incubation for 3 days). For the detection of L. acidophilus LaCH-5, the Rogosa plates were incubated microaerophilically. Beerens and Rogosa agars were also used with tetracycline supplementation $\left(8 \mu \mathrm{g} \mathrm{ml}^{-1}\right)$, as B. animalis subsp. lactis $\mathrm{Bb}-12$ is intermediately resistant to tetracycline.

Isolates representing all of the different potential Lactobacillus and Bifidobacterium colony morphologies, or, in the case of uniform colony morphology, random isolates, were collected from Beerens- and Rogosa-based media (five isolates from each medium where possible) for comparison of the species distribution in saliva and faeces.

Fingerprinting of bifidobacteria and lactobacilli by randomly amplified polymorphic DNA (RAPD). A total of 587 isolates from Beerens medium were analysed by RAPD using primer OPA-2 ( $5^{\prime}$ TGCCGAGCTG- $3^{\prime}$ ) and 574 isolates from Rogosa were analysed by RAPD using primer OPA-3 (5'-AGTCAGCCAC-3') as described previously (Alander et al., 2001). The RAPD fingerprints of faecal and salivary isolates were compared with those of the B. animalis subsp. lactis $\mathrm{Bb}-12$ and $\mathrm{L}$. acidophilus $\mathrm{LaCH}-5$ strains by visual inspection. All types that looked different to the ingested probiotic strains were selected for further characterization.

Partial 16S rRNA gene sequencing. Isolates representing different RAPD types were identified by partial $16 \mathrm{~S}$ rRNA gene sequencing. Beerens isolates were amplified with Bif164-f ( $5^{\prime}$-GGGTGGTAATGCCGGATG-3') and Bif662-GC-r (5'-CGCCCGCCGCGCGCGGCGGGCGGGGCGGGGGCACGGGGGGCCACCGTTACACCGGGAA-3') as described by Satokari et al. (2001a). Rogosa isolates were amplified with BSF8/20 (5'-AGAGTTTGATCCTGGCTCAG-3') and BSR1541/20 (5'-AAGGAGGTGATCCAGCCGCA-3') (Wilmotte et al., 1993). The lactobacilli PCR mixture contained $0.2 \mathrm{mM}$ each dNTP, $0.2 \mu \mathrm{M}$ primer and 3 U Dynazyme II DNA polymerase in $1 \times$ Dynazyme buffer. PCR amplification was carried out in a thermocycler (UnoII, Biometra; 35 cycles with an annealing temperature of $56{ }^{\circ} \mathrm{C}$ ). The amplification products were checked, purified and further sequenced with primers Bif164-f or BSF8/20 as described previously (Maukonen et al., 2006b).

PCR-denaturing gradient gel electrophoresis (DGGE) analysis. DNA was extracted as described by Maukonen et al. (2006b). Part of the $16 \mathrm{~S}$ rRNA gene $\left(\mathrm{V}_{6}-\mathrm{V}_{8}\right.$ hypervariable region) was PCR amplified for the detection of predominant bacterial microbiota using primers U968-f + GC (5'-CGCCCGGGGCGCGCCCCGGGCGGGGCGGGGGCACGGGGGGAACGCGAAGAACCTTA-3') and U1401-r (5'CGGTGTGTACAAGACCC-3') (Nübel et al., 1996), as described by Mättö et al. (2005). Primers Bif164-f and Bif662-GC-r were used to evaluate the diversity and temporal stability of bifidobacteria according to Satokari et al. (2001a). Primers Bifl64mod-f (5'GGGTGGTAATACCGGATG-3') and Bif662-GC-r (Satokari et al., 2001b) were used for the detection of B. animalis subsp. lactis Bb-12. The Lactobacillus group, which comprises the genera Lactobacillus, Leuconostoc, Pediococcus and Weissella, was amplified using primers Lac1 (5' -AGCAGTAGGGAATCTTCCA-3' and Lac2GC (5' -CGCCCGCCGCGCCCCGCGCCCGGCCCGCCG CCCCCGCCCCATTYCACCGCTACACATG-3') (Walter et al., 2001), as described by Vanhoutte et al. (2004). The Erec group was PCR amplified using primers Ccoc- $\mathrm{f}$ (5'-AAATGACGGTACCTGACTAA-3'; Matsuki et al., 2002) and Ccoc-r + GC (5'-CGCCCGGGGCGCGCCCCGGGCGGGGCGGGGGCACGGGGGGCTTTGAGTTTCATTCTTGCGAA-3') according to Maukonen et al. (2006b).

PCR products were separated by polyacrylamide gels with a denaturing gradient of 38-60\% (predominant bacterial microbiota and Erec group), 45-55\% (bifidobacteria) or 30-60\% (Lactobacillus group) [where $100 \%$ is $7 \mathrm{M}$ urea and $40 \%(\mathrm{v} / \mathrm{v})$ deionized formamide] as described by Mättö et al. (2005). L. acidophilus LaCH-5 was added as a probiotic control lane to each Lactobacillus group-specific DGGE. Comparison of the PCR-DGGE profiles was performed as described previously (Maukonen et al., 2006b).

Statistical analysis. Means \pm SD were calculated for each experiment. Results with microbial numbers below the detection limit (log 4 for all microbial groups) were excluded from statistical analysis using Student's $t$-test (two-sample test assuming unequal variances).

\section{RESULTS AND DISCUSSION}

In the present study, both the culture-based approach (combined with fingerprinting of individual isolates) and PCR-DGGE were applied to study the intra-individual diversity and temporal stability of microbiota at two different sites, the oral cavity and the colon. To the best of our knowledge, there is only one previous study where the 
oral and faecal bacterial populations have been compared intra-individually using molecular techniques (Dal Bello \& Hertel, 2006). The probiotic product used in our study did not notably affect the stability of the predominant microbiota profile, Erec group profile or bifidobacterial profile (using non-modified primers that targeted only the intestinal bifidobacteria and not the ingested probiotic bifidobacteria), as the baseline DGGE profiles (before probiotic ingestion) were highly similar to those of the samples after 1 and 2 weeks of probiotic ingestion. All of these bacterial groups remained relatively stable in most of the subjects. Our study showed that, in the cases of predominant microbiota, bifidobacteria and Erec group bacteria, the faecal microbiota was more diverse than that in saliva. In addition, salivary and faecal DGGE profiles of these groups appeared to be substantially different. Interestingly, most subjects' faecal and salivary samples contained identical indigenous Lactobacillus species and genotypes.

Compliance was evaluated with culture-based techniques and DGGE analysis in this study. Probiotic strains were not found in any of the baseline samples, whereas RAPD types identical to B. animalis subsp. lactis Bb-12 were found from all faecal samples during probiotic ingestion (after 1 and 2 weeks). Ingested probiotic strains were not found in any of our salivary samples.

\section{Diversity and temporal stability of the predominant bacterial microbiota, Erec group, Lactobacillus group and bifidobacteria as detected with DGGE}

Predominant bacterial microbiota

DGGE analysis targeted to the predominant microbiota showed intra-individual diversity as well as uniqueness of both faecal and salivary microbiota (Fig. 1a). After comparison of all faecal- and saliva-based profiles, faecal profiles and salivary profiles formed two distinct clusters, with individual-based subclusters (data not shown). Indeed, the DGGE profiles of faecal and salivary samples differed substantially (mean similarity $23.7 \pm 7.1 \%$; Table 1). The predominant faecal microbiota was relatively stable temporally (mean similarity $83.3 \pm 5.3 \%$ ) and the salivary microbiota was mostly stable (mean similarity $92.2 \pm 2.5 \%$ ) during the study period (Table 2). This is consistent with previous work, which showed that the faecal microbiota is host specific and relatively stable temporally (Zoetendal et al., 1998; Vanhoutte et al., 2004; Maukonen et al., 2006b). Likewise, in a recent study by Rasiah et al. (2005), it was shown that the predominant salivary microbiota remained stable in one subject for 7 years. We found a significant difference between the number of amplicons detected in the faecal and salivary profiles (faeces $>$ saliva; $P<0.05$ ) (Table 2). Aas et al. (2005) showed that 20-30 different predominant species were found from most oral sites, utilizing $16 \mathrm{~S}$ rRNA gene clone libraries. Our universal DGGE results are in accordance with this previous work.

\section{Erec group}

DGGE analysis targeted to the Erec group showed intraindividual diversity as well as uniqueness of both faecal and salivary microbiota (Fig. 1b). Erec profiles of faecal samples clustered together according to subject, whereas salivary samples clustered according to subject in eight cases (data not shown). The similarity between faecal samples and salivary samples from the same subject at a given time point was very low or non-existent (mean similarity (a)

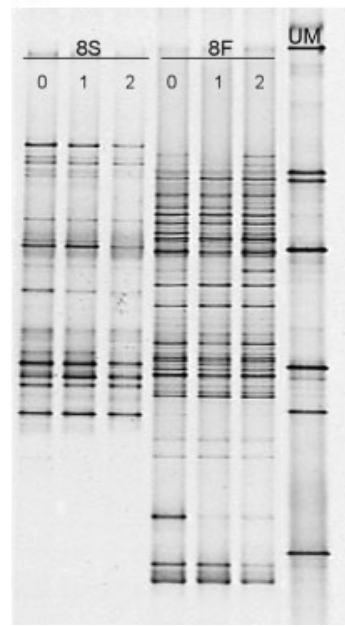

(b)

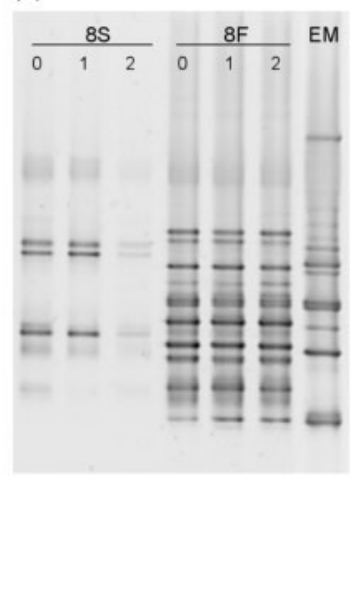

(c)

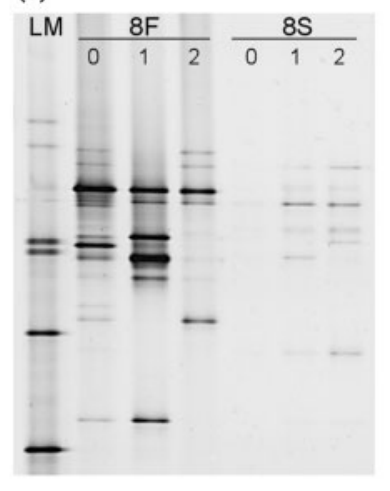

(d)

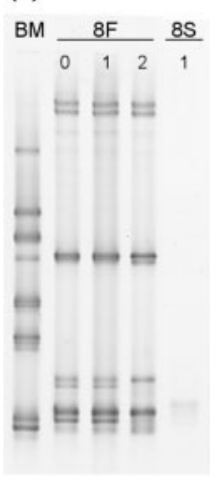

Fig. 1. Faecal and salivary DGGE profiles of a healthy subject. (a) Universal primers; (b) Erec group primers; (c) Lactobacillus group primers; (d) bifidobacteria primers. DNA was obtained from faecal samples (8F) and salivary samples (8S) at baseline (before probiotic consumption; lane 0), and after 1 and 2 weeks of probiotic consumption (lanes 1 and 2, respectively). BM, Bifidobacterial marker; EM, Erec group marker; LM, lactobacillus marker; UM, universal marker. 
Table 1. Intra-individual similarity values between a faecal sample and a salivary sample at a given time point for a given subject from ten healthy subjects before and during probiotic consumption

\begin{tabular}{|c|c|c|c|c|}
\hline \multirow[t]{2}{*}{ Analysis } & \multicolumn{4}{|c|}{ Similarity $(\%)^{\star}$} \\
\hline & Baseline $\dagger$ & 1 week & 2 weeks & Mean \\
\hline Faeces vs saliva $($ mean $\pm S D) \S$ & $25.7 \pm 10.9$ & $22.5 \pm 7.7$ & $22.9 \pm 8.7$ & $23.7 \pm 7.1$ \\
\hline Range§ & $10.8-43.8$ & $4.8-32.9$ & $9.5-37.7$ & $16.1-38.1$ \\
\hline \multicolumn{5}{|l|}{ Erec group of clostridia $\|$} \\
\hline Range $\$$ & $0.0-31.3$ & $0.0-32.2$ & $4.9-67.3$ & $1.6-39.0$ \\
\hline \multicolumn{5}{|l|}{ Lactobacillus group } \\
\hline Faeces vs saliva (mean $\pm \mathrm{SD}) \S$ & $58.9 \pm 18.3$ & $60.2 \pm 8.3$ & $58.7 \pm 17.0$ & $58.6 \pm 11.2$ \\
\hline Range $\$$ & $26.7-85.7$ & $54.5-80.0$ & $26.7-80.0$ & $40.3-74.3$ \\
\hline \multicolumn{5}{|l|}{ Bifidobacteria } \\
\hline Faeces vs saliva $($ mean $\pm S D) \S \#$ & $19.8 \pm 13.2$ & $23.9 \pm 28.2$ & $26.6 \pm 32.7$ & $26.4 \pm 27.9$ \\
\hline
\end{tabular}

*Similarity values were analysed using BioNumerics 4.50 software. Amplicons with the total surface area of at least $1 \%$ were included in the similarity analysis.

$†$ Sample before 2 weeks of probiotic consumption.

$\ddagger$ Partial $16 \mathrm{~S}$ rRNA gene $\left(\mathrm{V}_{6}-\mathrm{V}_{8}\right.$ hypervariable region).

§The salivary and faecal samples were compared only intra-individually, that is, for example, a faecal sample of subject A taken at baseline was compared only with the salivary sample of subject A taken at baseline.

|lClostridial phylogenetic cluster XIVa (Collins et al., 1994).

SLactobacillus group was comprised the genera Lactobacillus, Leuconostoc, Pediococcus and Weissella.

\#Only half of the saliva samples gave a positive result after bifidobacteria-specific PCR.

$17.9 \pm 11.1 \%$; Table 1). Faecal samples of all subjects clustered together as one distinct cluster and salivary samples of all subjects clustered as another.

Maukonen et al. (2006b) showed that each band position in DGGE gels contained only one phylotype. We may therefore assume that the phylotypes present in the faeces and saliva are mostly different. Erec group bacteria were temporally stable in most cases (mean similarity: faeces $94 \pm 2.9 \%$; saliva $90.5 \pm 7.3 \%$ ) during our study period (Table 2), as has also been described previously (Maukonen et al., 2006b). In this study, the Erec group diversity in salivary samples was significantly lower than in the faecal samples $(P<0.05)$. Nonetheless, we found between 3 and 12 amplicons from each sample (Table 2), indicating that the diversity of the Erec group in saliva in some subjects may be slightly greater that that shown previously with other techniques (Downes et al., 2001; Paster et al., 2001).

\section{Lactobacillus group}

In this study, the DGGE profiles of the faeces- and salivaderived Lactobacillus group were more similar to each other (mean similarity $58.6 \pm 11.2 \%$; Table 1 ) than the faeces- and saliva-derived profiles of the other bacterial groups studied. In addition, faecal Lactobacillus group profiles of nearly all subjects were fairly unstable (mean similarity $69.1 \pm 7.3 \%$; Table 2, Fig. 1c), whereas salivary Lactobacillus group profiles remained rather stable (mean similarity $89.8 \pm 7.5 \%$; Table 2 ). Based on the comparisons made between different sampling points (baseline without probiotic consumption vs samples during probiotic consumption), the ingested L. acidophilus LaCH-5 strain, which was seen in the faecal lactobacilli DGGE profile during probiotic ingestion, does not alone explain the instability.

As the LaCH-5 strain produced only a single band, it did not contribute to a considerable change in the similarity values between the samples. In the salivary samples, there were no amplicons that were identical to those of $L$. acidophilus LaCH-5. In BioNumerics analysis, the lack of a stable and host-specific Lactobacillus group population resulted in a complete lack of subject grouping in faecal samples and sample type grouping (faeces vs saliva). This lack of subject grouping has also been reported for faecal samples by Vanhoutte et al. (2004). The number of amplicons detected in our study was higher in faecal samples compared with salivary samples (Table 2).

\section{Bifidobacteria}

In this study, DGGE profiles of faecal samples of a given subject clustered together in nine out of ten subjects (data not shown). In these cases, the faecal bifidobacterial population remained fairly stable temporally (one subject was unstable) (Table 2, Fig. 1d), as has also been found by, for example, Satokari et al. (2001a). Only about half of the 
Table 2. Intra-individual similarity values and diversity of DGGE profiles of human faecal and salivary samples obtained at three different time points from ten healthy subjects

\begin{tabular}{|c|c|c|c|c|c|c|c|c|}
\hline \multirow[t]{2}{*}{ Analysis } & \multicolumn{4}{|c|}{ Similarity $(\%)^{\star}$} & \multicolumn{4}{|c|}{ Diversity $\dagger$} \\
\hline & 0 vs 1 & 0 vs 2 & 1 vs 2 & Mean & 0 week & 1 week & 2 weeks & Mean \\
\hline \multicolumn{9}{|l|}{$\begin{array}{l}\text { Predominant } \\
\text { bacteria } \neq\end{array}$} \\
\hline Faeces $($ mean $\pm \mathrm{SD})$ & $84.3 \pm 7.8$ & $81.0 \pm 7.6$ & $84.7 \pm 4.9$ & $83.3 \pm 5.3$ & $33.7 \pm 4.2$ & $35.8 \pm 4.4$ & $35.1 \pm 4.4$ & $34.9 \pm 4.0$ \\
\hline Range & $70.3-92.8$ & $70.0-90.6$ & $75.6-92.2$ & $72.0-90.9$ & 25-39 & $27-42$ & 27-41 & $26.3-40.7$ \\
\hline Saliva (mean $\pm \mathrm{SD})$ & $92.1 \pm 3.3$ & $91.4 \pm 2.5$ & $93.2 \pm 4.4$ & $92.2 \pm 2.5$ & $23.9 \pm 2.9$ & $23.1 \pm 2.2$ & $23.8 \pm 2.9$ & $23.6 \pm 2.4$ \\
\hline Range & $86.0-95.8$ & $87.2-94.2$ & $82.9-98.0$ & $88.8-95.3$ & 20-27 & 19-26 & 19-28 & $19.3-26.7$ \\
\hline \multicolumn{9}{|l|}{ Erec group $\S$} \\
\hline Faeces $($ mean $\pm \mathrm{SD})$ & $95.1 \pm 2.8$ & $92.3 \pm 4.7$ & $94.8 \pm 2.0$ & $94.0 \pm 2.9$ & $15.1 \pm 2.4$ & $15.5 \pm 2.3$ & $14.8 \pm 1.9$ & $15.1 \pm 2.0$ \\
\hline Range & 89.9-98.6 & $81.6-97.5$ & $90.0-97.3$ & $87.1-96.9$ & $11-19$ & 13-19 & $12-19$ & $12.3-18.7$ \\
\hline Saliva $($ mean $\pm \mathrm{SD})$ & $92.9 \pm 7.7$ & $86.7 \pm 11.8$ & $92.0 \pm 9.2$ & $90.5 \pm 7.3$ & $7.4 \pm 2.1$ & $7.4 \pm 1.6$ & $7.7 \pm 2.0$ & $7.5 \pm 1.7$ \\
\hline Range & $73.8-98.2$ & $66.5-98.0$ & $70.0-99.4$ & $77.2-98.0$ & 3-11 & 5-10 & 5-12 & $4.7-9.7$ \\
\hline \multicolumn{9}{|l|}{ Lactobacillus group\| } \\
\hline Faeces $($ mean $\pm \mathrm{SD})$ & $70.0 \pm 8.1$ & $68.2 \pm 11.9$ & $70.7 \pm 14.0$ & $69.1 \pm 7.3$ & $12.0 \pm 5.3$ & $10.9 \pm 2.8$ & $11.0 \pm 2.4$ & $11.5 \pm 3.0$ \\
\hline Range & $60.0-85.7$ & $50.0-85.7$ & $50.0-88.9$ & $61.0-85.7$ & $7-22$ & $7-15$ & $7-14$ & $8.0-16.3$ \\
\hline Saliva $($ mean $\pm \mathrm{SD})$ & $92.2 \pm 13.9$ & $87.6 \pm 11.0$ & $89.5 \pm 6.5$ & $89.8 \pm 7.5$ & $7.0 \pm 2.8$ & $7.9 \pm 3.1$ & $7.0 \pm 3.4$ & $7.3 \pm 2.9$ \\
\hline Range & $66.7-100$ & $66.7-100$ & $80.0-100$ & $76.9-100$ & $3-13$ & 5-14 & 4-15 & $3.7-14.0$ \\
\hline \multicolumn{9}{|l|}{ Bifidobacteria } \\
\hline Faeces $($ mean $\pm S D)$ & $94.0 \pm 3.5$ & $87.1 \pm 10.8$ & $82.3 \pm 16.2$ & $87.8 \pm 9.6$ & $9.1 \pm 2.8$ & $8.8 \pm 2.4$ & $9.1 \pm 3.2$ & $9.0 \pm 2.6$ \\
\hline Range & $90.9-99.6$ & $68.2-97.8$ & $52.5-98.1$ & $70.7-97.1$ & 6-15 & $7-15$ & 4-14 & $5.3-14.7$ \\
\hline Saliva $($ mean $\pm \mathrm{SD})$ & $84.7 \pm 17.9$ & $97.9 \pm 2.0$ & $89.2 \pm 15.7$ & $86.4 \pm 16.0$ & $4.5 \pm 1.9$ & $5.8 \pm 1.5$ & $4.0 \pm 1.7$ & $4.4 \pm 1.4$ \\
\hline Range & $62.3-98.9$ & $95.5-99.7$ & $65.6-98.0$ & $62.3-98.0$ & $2-7$ & 4-8 & $2-7$ & $3.0-6.7$ \\
\hline
\end{tabular}

${ }^{\star}$ Similarity values were calculated using BioNumerics 4.50 software. Amplicons with a total surface area of at least $1 \%$ were included in the similarity analysis. 0, baseline (before probiotic consumption); 1, 1 week of probiotic consumption; 2, 2 weeks of probiotic consumption.

$\dagger$ Diversity is presented as the number of bands making up $>1 \%$ of the total profile as detected by the BioNumerics 4.50 software.

$\ddagger$ Partial $16 \mathrm{~S}$ rRNA gene $\left(\mathrm{V}_{6}-\mathrm{V}_{8}\right.$ hypervariable region).

§Clostridial phylogenetic cluster XIVa (Collins et al., 1994).

ILactobacillus group was comprised the genera Lactobacillus, Leuconostoc, Pediococcus and Weissella.

SOnly half of the salivary samples gave a positive result after bifidobacteria-specific PCR.

salivary samples (17/30 samples) gave a positive PCR result, although several additional variations to the PCR protocol were tested (data not shown). The salivary bifidobacterial populations were temporally stable in three subjects and unstable in one subject (a different subject from the one who had an unstable faecal bifidobacterial population; data not shown). Of the remaining six subjects, only one sample from three subjects and two samples from another subject produced a PCR product, thus not allowing temporal stability to be determined. The bifidobacterial profiles did not cluster according to sample type, even though the similarity between faecal and salivary samples collected at the same time was low. The faecal samples contained significantly more amplicons than the salivary samples at all sampling time points $(P<0.05)$ (Table 2). As the PCR primers used for the DGGE-based diversity assessment had one base mismatch (Satokari et al., 2001b) with the sequence of the ingested B. animalis subsp. lactis $\mathrm{Bb}-12$, this strain was not seen in the bifidobacterial DGGE profiles and therefore did not affect the temporal stability of the faecal and salivary profiles. However, Bb-12 was detected in faecal samples from seven of the ten subjects using DGGE targeting $B$. animalis subsp. lactis $\mathrm{Bb}-12$. There were no amplicons that migrated at identical positions to those of B. animalis subsp. lactis $\mathrm{Bb}-$ 12 in any of the salivary samples.

\section{Culture}

Mean numbers of culturable bacteria on media without tetracycline at different sampling occasions are shown in Fig. 2. The number of culturable bacteria remained stable during probiotic consumption in both faecal and salivary samples. The number of culturable anaerobic bacteria was significantly higher in faeces (mean $\log 10.5$ c.f.u. $\mathrm{g}^{-1}$ ) than in saliva (mean $\log 8.3$ c.f.u. $\left.\mathrm{g}^{-1}\right)(P<0.05)$, whereas the number of culturable aerobic bacteria was significantly higher in saliva (mean $\log 7.8$ c.f.u. $\mathrm{g}^{-1}$ ) than in faeces (mean $\log 7.1$ c.f.u. $\left.\mathrm{g}^{-1}\right)(P<0.05)$. The numbers of both bifidobacteria and lactobacilli were significantly higher in 


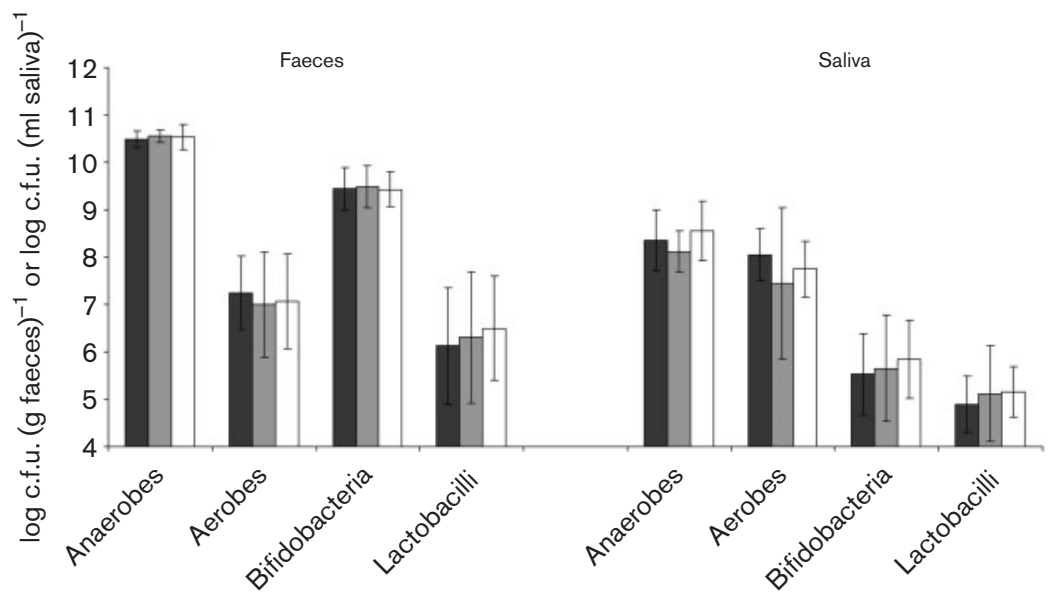

Fig. 2. Bacterial numbers (counts of bacteria growing on non-selective and bifidobacteriaor lactobacilli-selective culture media) in faecal and salivary samples of ten healthy volunteers. The samples were obtained at baseline before probiotic consumption (black bars), after 1 week of probiotic consumption (grey bars) and after 2 weeks of probiotic consumption (white bars).

faeces compared with saliva $(P<0.05)$ (Fig. 2). The numbers of culturable bacteria found in salivary and faecal samples were in accordance with previous studies (Sanyal \& Russel, 1978; Matsuki et al., 1999; Tannock et al., 2000).

Isolates with an identical RAPD type to the ingested $B$. animalis subsp. lactis $\mathrm{Bb}-12$ strain were recovered from faecal samples but not from the salivary samples of all subjects during probiotic consumption (samples from 1 and 2 weeks), whereas isolates of L. acidophilus LaCH-5 strain were recovered from faecal samples of all subjects after 1 week of probiotic consumption and from nine out of ten subjects after 2 weeks.

From each subject, three to six indigenous salivary lactobacilli RAPD types and one to five indigenous faecal lactobacilli RAPD types were detected (Table 3 ). In addition, identical indigenous lactobacilli RAPD types were found in saliva and faeces for eight of the ten subjects (Table 3 ). These included Lactobacillus rhamnosus, Lactobacillus gasseri, Lactobacillus paracasei, Lactobacillus plantarum group (comprising L. plantarum, Lactobacillus arizonensis and Lactobacillus pentosus) and a Lactobacillus sp.

In a study by Dal Bello \& Hertel (2006), Lactobacillus populations of salivary and oral samples of three subjects were compared by culture and RAPD typing in addition to DGGE. They found that L. gasseri, L. paracasei, $L$. rhamnosus and Lactobacillus vaginalis were most commonly detected among the predominant lactobacilli in the saliva and faeces of their three subjects. However, we only found L. vaginalis from one subject's saliva and none of the faecal samples of our subjects. L. gasseri, L. paracasei and $L$. rhamnosus were commonly detected from our subjects. The similarity of the faecal and salivary Lactobacillus populations found in this and another study (Dal Bello \& Hertel, 2006) indicate that at least some Lactobacillus species/ strains are able to live in different niches in the human orogastrointestinal tract, although the oral cavity and colon differ in several aspects including redox potential, nutrients, mucosal surfaces and co-existing members of the specific microbial community.
Between two and eight indigenous RAPD types were found per subject from faecal Beerens isolates and between two and nine per subject from salivary Beerens isolates. However, only one to seven faecal and zero to two salivary RAPD types per subject were confirmed to be bifidobacteria (after bifidobacteria-specific PCR with primers Bif164-f and Bif662-GC-r; Satokari et al., 2001a) (Table 4 ), indicating that most salivary Beerens biotypes were not bifidobacteria. Whereas $80 \%$ (37/46; Table 4) of the faecal Beerens biotypes were bifidobacteria. No identical indigenous RAPD types were found between saliva and faeces. After sequencing of the different bifidobacteria RAPD types, multiple indigenous bifidobacterial genotypes, including Bifidobacterium longum, Bifidobacterium adolescentis, Bifidobacterium catenulatum/ Bifidobacterium pseudocatenulatum, Bifidobacterium bifidum and Bifidobacterium angulatum were detected in faeces within an individual, whilst only Bifidobacterium dentium and $B$. bifidum were detected from saliva (Table 4 ). We found $B$. dentium in the saliva of five subjects. $B$. dentium was not found in faecal samples, which is consistent with a published culture-based analysis (Mättö et al., 2004). However, it has been found in faeces in DNA-based studies (Matsuki et al., 1999). We used culture-based identification in the present study, as we wanted to see whether the bifidobacteria detected from the faeces were alive and therefore most likely to represent autochthonous strains. The levels of $B$. dentium in our salivary samples gave a mean value of $2 \times 10^{5}$ c.f.u. $\mathrm{ml}^{-1}$, which accounts for $10^{6}-10^{8}$ cells in $1000 \mathrm{ml}$ saliva; this is the mean quantity of saliva ingested daily (Nisengard \& Newman, 1994). Therefore, the B. dentium strains found in the faecal samples by DNA-based methods may originate from saliva and may actually be allochthonous.

\section{Conclusions}

In conclusion, the predominant bacteria, bifidobacteria and Erec group bacteria, of the oral cavity and intestines were generally stable during probiotic consumption, 
Table 3. Heterogeneity of indigenous Lactobacillus populations

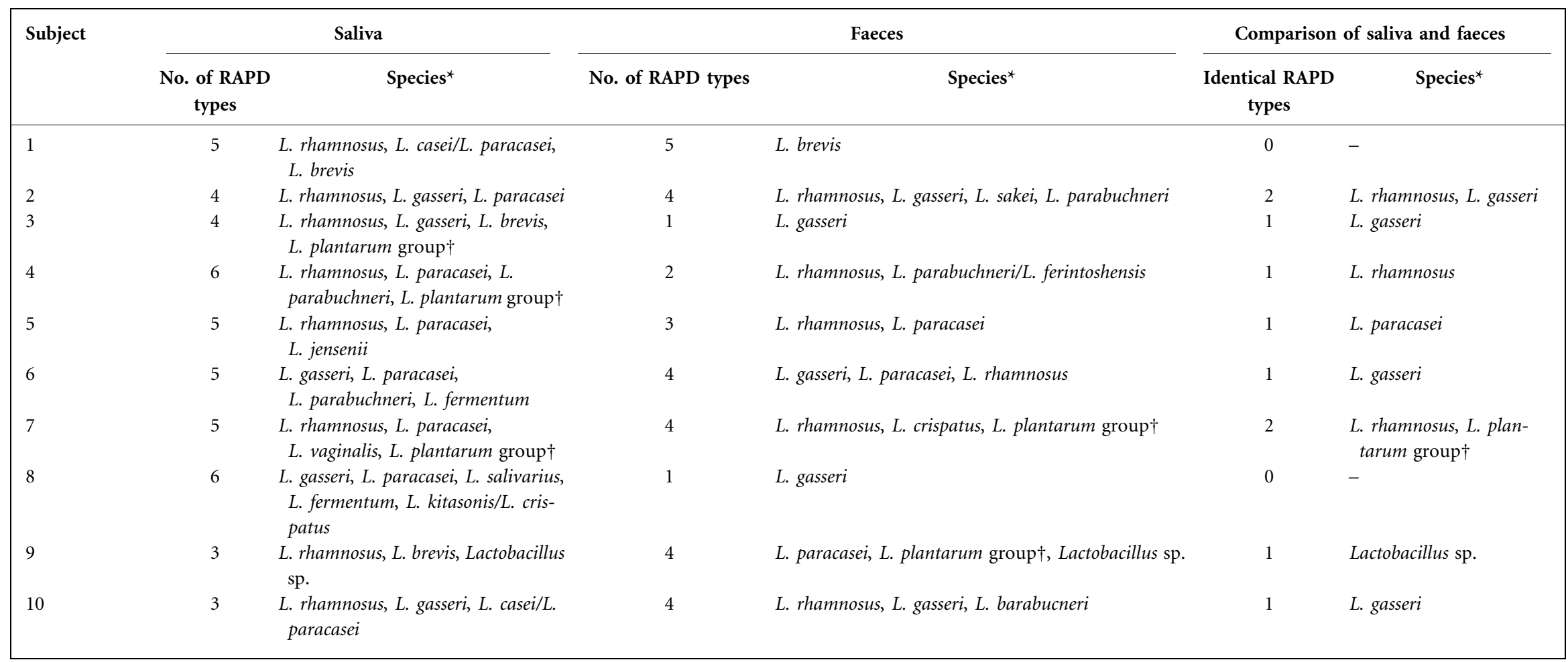

${ }^{\star}$ Determined by $16 \mathrm{~S}$ rRNA gene sequencing.

$\dagger L$. plantarum group: L. plantarum, L. arizonensis and L. pentosus. 
Table 4. Heterogeneity of indigenous Bifidobacterium populations

\begin{tabular}{|c|c|c|c|c|c|c|}
\hline \multirow[t]{2}{*}{ Subject } & \multicolumn{3}{|c|}{ Saliva } & \multicolumn{3}{|r|}{ Faeces } \\
\hline & $\begin{array}{c}\text { No. of initial } \\
\text { RAPD } \\
\text { types }^{\star}\end{array}$ & $\begin{array}{c}\text { No. of } \\
\text { confirmed } \\
\text { RAPD types } \dagger\end{array}$ & Species $\ddagger$ & $\begin{array}{c}\text { No. of } \\
\text { initial } \\
\text { RAPD types }\end{array}$ & $\begin{array}{c}\text { No. of } \\
\text { confirmed } \\
\text { RAPD types } \dagger\end{array}$ & Species $\ddagger$ \\
\hline 1 & 5 & 2 & $\begin{array}{l}\text { B. dentium, } \\
\text { B. bifidum }\end{array}$ & 4 & 1 & B. longum \\
\hline 3 & 4 & 2 & B. dentium & 3 & 2 & B. longum \\
\hline 4 & 9 & 1 & B. dentium & 2 & 2 & B. longum, B. catenulatum/B. pseudocatenulatum \\
\hline 5 & 3 & 0 & - & 4 & 4 & B. longum, B. adolescentis \\
\hline 6 & 4 & 0 & - & 5 & 5 & $\begin{array}{l}\text { B. longum, } B \text {. adolescentis, B. bifidum, } B \text {. } \\
\text { angulatum }\end{array}$ \\
\hline 10 & 2 & 1 & B. dentium & 4 & 3 & B. longum, B. adolescentis \\
\hline
\end{tabular}

${ }^{\star}$ Bifidobacterium-like isolates that were initially RAPD typed.

$\dagger$ Number of RAPD types of the bifidobacterial isolates that gave a positive result with a bifidobacteria-specific PCR (Satokari et al., 2001a).

\$Determined by $16 \mathrm{~S}$ rRNA gene sequencing.

showing more diversity in faeces than saliva, and having different species compositions for the two sampling sites. In contrast, the lactobacilli, which are known to inhabit several ecological niches, showed temporal instability in both faeces and saliva. Furthermore, faecal and salivary samples contained identical indigenous Lactobacillus genotypes (L. rhamnosus, L. gasseri, L. paracasei, L. plantarum group and a Lactobacillus sp.) in most subjects.

\section{ACKNOWLEDGEMENTS}

Ms Marja-Liisa Jalovaara, Ms Niina Torttila and Ms Helena Hakuli are thanked for their skilful technical assistance. This study was carried out with financial support from the Academy of Finland (project 209758) and the Commission of the European Communities, specific RTD programme 'Quality of Life and Management of Living Resources', QLK2-CT-2002-00843, 'Antimicrobial resistance transfer from and between Gram-positive bacteria of the digestive tract and consequences for virulence.' This work does not necessarily reflect its views and in no way anticipates the Commission's future policy in this area.

\section{REFERENCES}

Aas, J. A., Paster, B. J., Stokes, L. N., Olsen, I. \& Dewhirst, F. E. (2005). Defining the normal bacterial flora of the oral cavity. J Clin Microbiol 43, 5721-5732.

Alander, M., Mättö, J., Kneifel, W., Johansson, M., Kögler, B., Crittenden, R., Mattila-Sandholm, T. \& Saarela, M. (2001). Effect of galacto-oligosaccharide supplementation on human faecal microflora and on survival and persistence of Bifidobacterium lactis Bb-12 in the gastrointestinal tract. Int Dairy J 11, 817-825.
Atlas, R. M. (1997). Cary-Blair transport medium. In Handbook of Microbiological Media, p. 253. Edited by L. C. Parks. Boca Raton, FL: CRC Press.

Beerens, H. (1991). Detection of bifidobacteria by using propionic acid as a selective agent. Appl Environ Microbiol 57, 2418-2419.

Berg, R. D. (1996). The indigenous gastrointestinal microflora. Trends Microbiol 4, 430-435.

Collins, M. D., Lawson, P. A., Willems, A., Cordoba, J. J., FernandezGarayzabal, J., Garcia, P., Cai, J., Hippe, H. \& Farrow, J. A. E. (1994). The phylogeny of the genus Clostridium: proposal of five new genera and eleven new species combinations. Int J Syst Bacteriol 44, 812-826.

Dal Bello, F. \& Hertel, C. (2006). Oral cavity as natural reservoir for intestinal lactobacilli. Syst Appl Microbiol 29, 69-76.

Downes, J., Munson, M. A., Spratt, D. A., Kononen, E., Tarkka, E., Jousimies-Somer, H. \& Wade, W. G. (2001). Characterisation of Eubacterium-like strains from oral infections. J Med Microbiol 50, 947-951.

Eckburg, P. B., Bik, E. M., Bernstein, C. N., Purdom, E., Dethlefsen, L., Sargent, M., Gill, S. R., Nelson, K. E. \& Relman, D. A. (2005). Diversity of the human intestinal microbial flora. Science 308, 1635-1638.

Franks, A. H., Harmsen, H. J. M., Raangs, G. C., Jansen, G. J., Schut, F. \& Welling, G. W. (1998). Variations in bacterial populations in human feces measured by fluorescent in situ hybridization with group-specific 16S rRNA-targeted oligonucleotide probes. Appl Environ Microbiol 64, 3336-3345.

Li, Y., Ku, C. Y. S., Xu, J., Saxena, D. \& Caufield, P. W. (2005). Survey of oral microbial diversity using PCR-based denaturing gradient gel electrophoresis. J Dent Res 84, 559-564.

Matsuki, T., Watanabe, K., Tanaka, R., Fukuda, M. \& Oyaizu, H. (1999). Distribution of bifidobacterial species in human intestinal 
microflora examined with 16S rRNA-gene-targeted species-specific primers. Appl Environ Microbiol 65, 4506-4512.

Matsuki, T., Watanabe, K., Fujimoto, J., Miyamoto, Y., Takada, T., Matsumoto, K., Oyaizu, H. \& Tanaka, R. (2002). Development of $16 \mathrm{~S}$ rRNA-gene-targeted group-specific primers for the detection and identification of predominant bacteria in human feces. Appl Environ Microbiol 68, 5445-5451.

Mättö, J., Malinen, E., Suihko, M.-L., Alander, M., Palva, A. \& Saarela, M. (2004). Genetic heterogeneity and functional properties of intestinal bifidobacteria. J Appl Microbiol 97, 459-470.

Mättö, J., Maunuksela, L., Kajander, K., Palva, A., Korpela, R., Kassinen, A. \& Saarela, M. (2005). Composition and temporal stability of gastrointestinal microbiota in irritable bowel syndrome - a longitudinal study in IBS and control subjects. FEMS Immunol Med Microbiol 43, 213-222.

Maukonen, J., Satokari, R., Mättö, J., Söderlund, H., MattilaSandholm, T. \& Saarela, M. (2006a). Prevalence and temporal stability of selected clostridial groups in irritable bowel syndrome in relation to predominant fecal bacteria. J Med Microbiol 55, 625-633.

Maukonen, J., Mättö, J., Satokari, R., Söderlund, H., MattilaSandholm, T. \& Saarela, M. (2006b). PCR-DGGE and RT-PCRDGGE show diversity and short-term temporal stability in Clostridium coccoides-Eubacterium rectale group in human intestinal microbiota. FEMS Microbiol Ecol 58, 517-528.

Nisengard, R. J. \& Newman, M. G. (1994). Oral Microbiology and Immunology, Philadelphia, PA: W.B. Saunders.

Nübel, U., Engelen, B., Felske, A., Snaidr, J., Wieshuber, A., Amann, R. I., Ludwig, W. \& Backhaus, H. (1996). Sequence heterogeneities of genes encoding $16 \mathrm{~S}$ rRNAs in Paenibacillus polymyxa detected by temperature gradient gel electrophoresis. J Bacteriol 178, 5636-5643.

Paster, B. J., Boches, S. K., Galvin, J. L., Ericson, R. E., Lau, C. N., Levanos, V. A., Sahasrabudhe, A. \& Dewhirst, F. E. (2001). Bacterial diversity in human subgingival plaque. J Bacteriol 183, 3770-3783.

Rams, T. E., Feik, D. \& Slots, J. (1990). Staphylococci in human periodontal diseases. Oral Microbiol Immunol 5, 29-32.

Rasiah, I. A., Wong, L., Anderson, S. A. \& Sissons, C. H. (2005). Variation in bacterial DGGE patterns from human saliva: over time, between individuals and in corresponding dental plaque microcosm. Arch Oral Biol 50, 779-787.

Sanyal, B. \& Russel, C. (1978). Nonsporing, Gram-positive rods in saliva and the gingival crevice of humans. Appl Environ Microbiol 35, 670-678.
Satokari, R. M., Vaughan, E. E., Akkermans, A. D., Saarela, M. \& de Vos, W. M. (2001a). Bifidobacterial diversity in human feces detected by genus-specific polymerase chain reaction and denaturing gradient gel electrophoresis. Appl Environ Microbiol 67, 504-513.

Satokari, R. M., Vaughan, E. E., Akkermans, A. D. L., Saarela, M. \& de Vos, W. M. (2001b). Polymerase chain reaction and denaturing gradient gel electrophoresis monitoring of fecal Bifidobacterium populations in a prebiotic and probiotic feeding trial. Syst Appl Microbiol 24, 227-231.

Sghir, A., Gramet, G., Suau, A., Rochet, V., Pochart, P. \& Doré, J. (2000). Quantification of bacterial groups within human fecal flora by oligonucleotide probe hybridization. Appl Environ Microbiol 66, 2263-2266.

Suau, A., Bonnet, R., Sutren, M., Godon, J. J., Gibson, G., Collins, M. D. \& Doré, J. (1999). Direct analysis of genes encoding $16 \mathrm{~S}$ rRNA from complex communities reveals many novel molecular species within the human gut. Appl Environ Microbiol 65, 4799-4807.

Tannock, G. W., Munro, K., Harmsen, H. J. M., Welling, G. W., Smart, J. \& Gopal, P. K. (2000). Analysis of the fecal microflora of human subjects consuming a probiotic product containing Lactobacillus rhamnosus DR20. Appl Environ Microbiol 66, 2578-2588.

Thiel, R. \& Blaut, M. (2005). An improved method for the automated enumeration of fluorescently labelled bacteria in human faeces. J Microbiol Methods 61, 369-379.

Vanhoutte, T., Huys, G., de Brandt, E. \& Swings, J. (2004). Temporal stability analysis of the microbiota in human feces by denaturing gradient gel electrophoresis using universal and group-specific $16 \mathrm{~S}$ rRNA gene primers. FEMS Microbiol Ecol 48, 437-446.

Walter, J., Hertel, C., Tannock, G. W., Lis, C. M., Munro, K. \& Hammes, W. (2001). Detection of Lactobacillus, Pediococcus, Leuconostoc, and Weissella species in human feces by using group-specific PCR primers and denaturating gradient gel electrophoresis. Appl Environ Microbiol 67, 2578-2585.

Wilmotte, A., van der Auwera, G. \& de Wachter, R. (1993). Structure of the $16 \mathrm{~S}$ ribosomal RNA of the thermophilic cyanobacterium Chlorogloeopsis HTF ('Mastigocladus laminosus HTF') strain PCC7518, and phylogenetic analysis. FEBS Lett 317, 96-100.

Zoetendal, E. G., Akkermans, A. D. \& de Vos, W. M. (1998). Temperature gradient gel electrophoresis analysis of $16 \mathrm{~S}$ rRNA from human fecal samples reveals stable and host-specific communities of active bacteria. Appl Environ Microbiol 64, 3854-3859. 